\title{
Rapid detection and characterization of postpasteurization contaminants in pasteurized fluid milk
}

\author{
Alexander A. Alles, Martin Wiedmann, and Nicole H. Martin ${ }^{1}$ \\ Milk Quality Improvement Program, Department of Food Science, Cornell University, Ithaca, NY 14853
}

\begin{abstract}
Microbial spoilage of pasteurized fluid milk is typically due to either (1) postpasteurization contamination (PPC) with psychrotolerant gram-negative bacteria (predominantly Pseudomonas) or (2) growth of psychrotolerant sporeformers (e.g., Paenibacillus) that have the ability to survive pasteurization when present as spores in raw milk, and to subsequently grow at refrigeration temperatures. While fluid milk quality has improved over the last several decades, continued reduction of PPC is hampered by the lack of rapid, sensitive, and specific methods that allow for detection of PPC in fluid milk, with fluid milk processors still often using time-consuming methods (e.g., Moseley keeping quality test). The goal of this project was to utilize a set of commercial fluid milk samples that are characterized by a mixture of samples with PPC due to psychrotolerant gram-negative bacteria and samples with presence and growth of psychrotolerant sporeforming bacteria to evaluate different approaches for rapid detection of PPC. Comprehensive microbiological shelf-life characterization of 105 pasteurized fluid milk samples obtained from 20 dairy processing plants showed that 60/105 samples reached bacterial counts $>20,000 \mathrm{cfu} / \mathrm{mL}$ over the shelf-life due to PPC with gram-negative bacteria. Among these 60 samples with evidence of gram-negative PPC spoilage over the shelflife, $100 \%$ (60/60) showed evidence of contamination with noncoliform, non-Enterobacteriaceae (EB) gramnegative bacteria (e.g., Pseudomonas), 20\% (12/60) showed evidence of contamination with coliforms, and $7 \%(4 / 60)$ showed evidence of contamination with noncoliform EB. Among the remaining 45 samples, 28 showed levels of gram-positive bacteria above 20,000 $\mathrm{cfu} / \mathrm{mL}$ and the remaining 17 samples did not exceed $20,000 \mathrm{cfu} / \mathrm{mL}$ over the shelf-life. Evaluation of the same set of 105 samples using 6 different approaches \{all possible combinations of 2 different enrichment
\end{abstract}

Received November 29, 2017.

Accepted May 5, 2018.

${ }^{1}$ Corresponding author: nhw6@cornell.edu protocols $\left(13^{\circ} \mathrm{C}\right.$ or $21^{\circ} \mathrm{C}$ for $\left.18 \mathrm{~h}\right)$ and 3 different plating media [crystal violet tetrazolium agar, EB Petrifilm (3M, St. Paul, MN), and Coliform Petrifilm]\} showed that enrichment at $21^{\circ} \mathrm{C}$ for $18 \mathrm{~h}$, followed by plating on crystal violet tetrazolium agar provided for the most sensitive, accelerated detection of samples that reached $>20,000 \mathrm{cfu} / \mathrm{mL}$ due to PPC with psychrotolerant gram-negatives $(70 \%$ sensitivity). These results show that tests still required and traditionally used in the dairy industry (e.g., coliform testing) are not suitable for monitoring for PPC. Rather, approaches that allow for detection of all gram-negative bacteria are essential for improved detection of PPC in fluid milk.

Key words: postpasteurization contamination, rapid method, Pseudomonas, indicator organism

\section{INTRODUCTION}

Although research has shown that fluid milk quality has consistently improved over the last 2 decades (Carey et al., 2005; Martin et al., 2012), postpasteurization contamination (PPC) is still a hurdle for some processors. In fact, some studies suggest that $\sim 40$ to $50 \%$ of conventionally pasteurized fluid milk shows evidence of PPC (Ranieri and Boor, 2009; S. J. Reichler, Cornell University, Ithaca, NY, unpublished). Postpasteurization contamination has previously been associated with rapid bacterial outgrowth (Schröder et al., 1982; Ranieri and Boor, 2009; Martin et al., 2012) and unacceptable sensorial properties (Hayes et al., 2002; Martin et al., 2012), both of which often lead to premature spoilage before the labeled product shelf-life (defined here as the sell-by date provided by the manufacturer). Because premature spoilage is a contributing cause of food loss, which accounts for approximately one-third of the fluid milk processed in the United States, at a value of $\$ 6.4$ billion (Buzby et al., 2014), reducing PPC is of great importance from a business, consumer, and sustainability perspective.

Postpasteurization contamination can be introduced into the fluid milk continuum at various points, but several research studies indicate that the filling equipment is an area that is particularly susceptible to 
contamination often due to lapses in good manufacturing practices (Eneroth et al., 1998; Ralyea et al., 1998; Gruetmacher and Bradley, 1999). Additionally, although stringent cleaning and sanitation programs reduce the incidence of $\mathrm{PPC}$, some contaminants that exist within resistant biofilms, or in niches that are inaccessible to cleaning and sanitizers, may not be effectively removed from processing equipment and lead to persistent PPC. Methods to detect PPC in fluid milk have primarily relied upon traditional indicator organisms used in the dairy industry. Coliforms have been used, for nearly a century, as indicator organisms in the dairy industry. For example, the US Pasteurized Milk Ordinance specifies a coliform limit of $10 \mathrm{cfu} / \mathrm{mL}$ for grade A pasteurized fluid milk by (FDA, 2015). Coliforms are heat labile and are very effectively eliminated by HTST pasteurization. Hence, coliform presence in pasteurized fluid milk can be expected to generally be due to re-introduction of these organisms after the heat step, unless coliforms were present in very high numbers (e.g., $>10^{6} \mathrm{cfu} / \mathrm{mL}$ ) in raw milk. Detection of coliforms in fluid milk thus is often considered an indication of unhygienic conditions or PPC. Testing for coliforms is also relatively fast, a desirable quality for indicator organisms, with many methods (e.g., Coliform Petrifilm) taking $24 \mathrm{~h}$ or less.

Despite the longstanding use of coliforms as indicators of PPC in fluid milk, many studies have identified Pseudomonas, a noncoliform, as the primary causative agent of PPC (Ternström et al., 1993; Eneroth et al., 1998; Deeth et al., 2002). Importantly, Pseudomonas and other noncoliform gram-negative bacteria are not recovered on coliform media and therefore may go undetected by current indicator tests. Testing methods that allow for the detection of coliforms, Pseudomonas, and other gram-negative bacteria (e.g., plating on crystal violet tetrazolium agar, CVTA) are not as rapid as coliform testing methods, typically requiring $48 \mathrm{~h}$ until results. A variety of methods with varying complexity and time-to-result have hence been developed to detect PPC in fluid milk and other fluid dairy products including impedance measurements (Bossuyt and Waes, 1983), direct epifluorescent filter technique (Griffiths et al., 1984), and bioluminescence assays (Griffiths, 1993). Additionally, several researchers have evaluated various selective enrichment procedures for rapid enumeration of PPC (Byrne et al., 1989). Although some of these methods show high correlation with the shelf-life performance of fluid milk (e.g., $\mathrm{r}=0.91$ for impedance methods using selective media; White, 1993) and some have rapid time to result (e.g., $<20 \mathrm{~h}$ for ATP testing following selective enrichment), many have high initial costs for equipment, require the use of numerous chemicals and reagents, or are complex to run. Importantly, almost all of the research that has been conducted on rapid detection of PPC in fluid milk was conducted in the 1980s when milk quality was significantly different and when milk quality issues due to PPC may have been due to different organisms (e.g., more common contamination with coliforms) and may have represented different contamination patterns (e.g., higher levels of initial contamination; Carey et al., 2005). Therefore, the goals of this study were to determine the overall population of bacterial contaminants contributing to PPC in a set of contemporary fluid milk samples and to test the ability of various methodologies, specifically those that do not require specialized or expensive equipment and complex steps, to detect PPC in these samples.

\section{MATERIALS AND METHODS}

\section{Sample Collection and Handling}

Pasteurized milk samples $(\mathrm{n}=105)$ were collected from 20 fluid milk processing facilities by Milk Quality Improvement Program (MQIP; Cornell University, Ithaca, NY) personnel from 2014 to 2015. Processing facilities were all enrolled in the Voluntary Shelf-Life Program, administered by MQIP, and were located in the northeast United States (New York, Maine, Vermont, New Hampshire, and Massachusetts). Facility size ranged from small, on-farm facilities (with processing capacities of approximately 0.5 million $\mathrm{kg} / \mathrm{yr}$ ) to large facilities (approximately 250 million $\mathrm{kg} / \mathrm{yr}$ ). Pasteurized fluid milk samples collected included whole-fat (minimum $3.25 \%$ milk fat, $\mathrm{n}=35)$, reduced-fat $(2 \%$ milk fat, $\mathrm{n}=22)$, low-fat $(1 \%$ milk fat, $\mathrm{n}=24)$, and nonfat $(<0.2 \%$ milk fat, $\mathrm{n}=24)$ milk in 12-ounce $(355$ $\mathrm{mL}, \mathrm{n}=2)$, pint (473 $\mathrm{mL}, \mathrm{n}=1)$, quart $(946 \mathrm{~mL}, \mathrm{n}=$ $10)$, half-gallon $(1.9 \mathrm{~L}, \mathrm{n}=91)$, or gallon $(3.8 \mathrm{~L}, \mathrm{n}=1)$ containers. None of the processors fortified their milk with nonfat dry milk. All products were pasteurized via HTST (15 facilities; 94 samples) or vat pasteurization (5 facilities; 11 samples) and packaged in glass bottles $(\mathrm{n}=9)$, high-density polyethylene jugs $(\mathrm{n}=92)$, or paperboard cartons $(\mathrm{n}=4)$. After being packed in coolers with ice packs or ice, milk samples were transported to the MQIP laboratory and stored at $4^{\circ} \mathrm{C}$ until the initial testing, performed within $48 \mathrm{~h}$ of sample collection.

\section{Shelf-Life Analysis, Rapid Shelf-Life Screening, and Bacterial Isolation}

On initial day of testing, pasteurized milk samples were handled and stored as described previously (Martin et al., 2012) in preparation for microbiological and organoleptic analyses, which were performed on each 
test day (day initial, d 7, 10, and 14) in accordance with Standard Methods for the Examination of Dairy Products (Laird et al., 2004). Extended shelf-life testing (on d 17 and 21) was performed on samples from a subset of processors that have a history of manufacturing high-quality products. Microbiological analyses conducted on each test day included total bacteria count on standard plate count (SPC) agar and total gram-negative bacteria count on CVTA with incubation at $32^{\circ} \mathrm{C}$ and $21^{\circ} \mathrm{C}$ for $48 \mathrm{~h}$, respectively. Samples were also inoculated onto 3M Enterobacteriaceae (EB) Petrifilm and 3M Coliform Petrifilm according to the manufacturer's instructions (3M, St. Paul, MN), followed by incubation at $32^{\circ} \mathrm{C}$ for $24 \mathrm{~h}$.

Additionally, on initial day of testing, 100-mL portions of each sample received a preliminary incubation (PI) at (1) $13^{\circ} \mathrm{C}$ for $18 \mathrm{~h}$ with subsequent plating on CVTA, EB Petrifilm, and Coliform Petrifilm, and (2) $21^{\circ} \mathrm{C}$ for $18 \mathrm{~h}$ with subsequent plating on CVTA, EB Petrifilm, and Coliform Petrifilm, following the plating procedure detailed above.

For every sample that showed positive results on media selective and differential for different gram-negatives (i.e., CVTA, EB Petrifilm, and Coliform Petrifilm), 2 isolates with typical gram-negative morphologies (for each combination of test day and medium) were streaked on brain heart infusion (BHI) agar (Difco, Franklin Lakes, NJ), followed by incubation at $32^{\circ} \mathrm{C}$ for $24 \mathrm{~h}$. Single colonies were subsequently grown in BHI broth at $32^{\circ} \mathrm{C}$ for $18 \mathrm{~h}$; isolates were then frozen and stored in $15 \%$ glycerol at $-80^{\circ} \mathrm{C}$; all pertinent isolate information is cataloged in Food Microbe Tracker (http://www.foodmicrobetracker.com). This procedure was also used to recover and preserve isolates from all SPC plates with counts $>20,000 \mathrm{cfu} / \mathrm{mL}$, selecting 1 colony for each unique morphology per set of duplicate plates.

\section{Sensory Defect Analysis}

For sensory defect analysis, samples were evaluated by a trained panel of 6 students and staff members from Cornell University as described in Martin et al. (2012). To participate on the defect judging panel, panelists were required to pass pre-screening and a test administered after completion of an initial defect judging training (representing approximately $15 \mathrm{~h}$ of training); panelists also received re-training (approximately $1 \mathrm{~h}$ ) twice a year. On each testing day (except d 7), panelists assigned a flavor criticism(s) and flavor score to each sample, with an average overall flavor quality score computed by Compusense 5 (Compusense Inc., Guelph, ON, Canada). Only nonflavored milk products were evaluated.

\section{Genus Identification by DNA Sequenced- Based Methods}

A total of 880 gram-negative bacterial isolates and 10 nonsporeforming gram-positive bacterial isolates were characterized by $16 \mathrm{~S}$ rDNA PCR and sequencing as described previously (Huck et al., 2007). Additionally, a total of 115 sporeformer isolates were characterized by rpoB PCR and sequencing as described previously with subsequent sequencing of the partial $16 \mathrm{~S}$ gene for new rpo $B$ allelic types (AT; Trmcic et al., 2015). Briefly, for both sequencing procedures, isolates were plated on $\mathrm{BHI}$ followed by incubation at $32^{\circ} \mathrm{C}$ for $24 \mathrm{~h}$. For $16 \mathrm{~S}$ rDNA PCR, $100 \mu \mathrm{L}$ of distilled $\mathrm{H}_{2} \mathrm{O}$ was inoculated with a colony and either (1) heated in a $1,200-\mathrm{W}$ microwave for $30 \mathrm{~s}$, or (2) heated in a thermal cycler at $95^{\circ} \mathrm{C}$ for $15 \mathrm{~min}$. For rpoB PCR, lysis was performed by heating an undiluted colony in a $1,200-\mathrm{W}$ microwave for 3 min. After PCR amplification, products were electrophoresed in $1.5 \%$ agarose gel at $120 \mathrm{~V}$ for 20 to 25 min. Upon treatment with ExoSap as previously described (Dugan et al., 2002), PCR products were sequenced using bidirectional Sanger sequencing as per manufacturer's instructions (Big Dye Sequencing Kit, Life Technologies Inc., Grand Island, NY). Partial 16S and $r p o B$ sequences were used to classify isolates to the genus or genus and species level based on similarity searches against the Ribosomal Database Project database (Cole et al., 2005) or our in-house rpoB database (MQIP, Cornell University, Ithaca, NY), respectively, using the Basic Local Alignment Search Tool (BLAST; McGinnis and Madden, 2004). For rpoB AT, a new AT was assigned if the 632 nucleotide sequences differed from a type strain in the rpo $B$ database by one or more nucleotides; species classification of a new rpoB AT included analysis of the 16S rRNA gene as described previously (Huck et al., 2007; Ivy et al., 2012).

\section{Data Analysis}

Data were managed in Microsoft Excel (version 2007, Microsoft Corp., Redmond, WA) and Microsoft Access (version 2016, Microsoft Corp.). All statistical modeling was performed in R (2016, R Foundation for Statistical Computing, Vienna, Austria) using the lme4 package. Bacterial count data were log-transformed before analyses. The detection limit was $1.0 \log \mathrm{cfu} / \mathrm{mL}$ for SPC and CVTA and $0.0 \log \mathrm{cfu} / \mathrm{mL}$ for EB and Coliform Petrifilm. A mixed-effect linear model was used to analyze the SPC data for samples with gram-negative PPC spoilage and gram-positive sporeformer spoilage (R). The model included test day, spoilage type, and corresponding interaction as fixed effects, and sample nested within plant as random effects (Bates et al., 
2014; Lenth, 2016; Wickham, 2016). To determine if sensory defect scores differed between spoilage types, a mixed-effects linear model was fitted to d 14 sensory scores with a single fixed effect of spoilage type. Random effects of plant, sampling, sample, panelist, sampling/plant interaction, and sampling/panelist interaction were included to account for the structure of the experiment. Standard errors and 95\% confidence intervals for the spoilage type estimates and pairwise contrasts were generated using a semiparametric bootstrap method with the bootMer function of lme4 in R.

Sensitivity was defined as the proportion of true positives that are correctly identified by a test [sensitivity $=$ true positive/(true positive + false negative)], whereas specificity was defined as the proportion of true negatives that are correctly identified by a test [specificity $=$ true negative/(true negative + false positive) ] (Altman and Bland, 1994a). A positive predictive value was defined as the proportion of true positives among those that test positive [positive predictive value $=$ true positive/(true positive + false positive)], whereas a negative predictive value was defined as the proportion of true negatives among those that test negative [negative predictive value $=$ true negative/(true negative + false negative)] (Altman and Bland, 1994b).

\section{RESULTS}

\section{Pasteurized Fluid Milk Sample Set Used Here Represents a Range of Gram-Negative and Gram-Positive Contamination Patterns}

Among the 105 fluid milk samples tested here, 84\% $(\mathrm{n}=88)$ tested reached $>20,000 \mathrm{cfu} / \mathrm{mL}$ during shelflife (Table 1). For 60 of these 88 samples, bacteria representing gram-negative genera were isolated from shelf-life samples with $>20,000 \mathrm{cfu} / \mathrm{mL}$ (spoilage classifications \#1 and 3 in Table 1). These 60 samples were designated as samples with gram-negative PPC spoilage. Gram-negative bacteria were also isolated after pre-incubation from 4 further samples with $>20,000$ $\mathrm{cfu} / \mathrm{mL}$, even though these 4 samples yielded only gram-positive isolates from the actual shelf-life samples (spoilage classification \#4 in Table 1). Therefore, a total of 64 samples showed evidence of contamination with gram-negative bacteria. Among these 64 samples, which reached $>20,000 \mathrm{cfu} / \mathrm{mL}$ and showed evidence of PPC, $100 \%$ (64/64) showed evidence of contamination with noncoliform, non-EB gram-negative bacteria (e.g., Pseudomonas), 19\% (12/64) showed evidence of contamination with coliforms, and $6 \%(4 / 64)$ showed evidence of contamination with noncoliform EB. Importantly, all of the samples that showed evidence of contamination with coliforms or noncoliform EB were also contaminated with noncoliform, non-EB gram-negative bacteria, specifically Pseudomonas (Supplemental Table S1; https://doi.org/10.3168/jds.2017-14216).

From the 64 samples with evidence of gram-negative contamination, a total of 880 gram-negative isolates were selected; these isolates were obtained from SPC, CVTA, EB Petrifilm, and Coliform Petrifilm plating media from both the PI methods and shelf-life testing. Sequence characterization and analysis of a 616 -bp fragment of the $16 \mathrm{~S}$ rDNA gene resulted in a subset of nonredundant gram-negative isolates $(\mathrm{n}=160)$, which were classified into 23 genera. Pseudomonas, which was isolated from 55 of the $64(86 \%)$ samples with evidence of gram-negative contamination, represented the dominant genus. Other gram-negative genera found in 5 or more samples with PPC, included Acinetobacter (22 samples), Cedecea (6 samples), and Raoultella (6 samples). Additionally, Hafnia was isolated from 4 samples that reached $20,000 \mathrm{cfu} / \mathrm{mL}$ during shelf-life as well as one additional sample that did not reach 20,000 $\mathrm{cfu} / \mathrm{mL}$ during shelf-life but still showed evidence of gram-negative contamination (isolation of gram-negative bacteria from shelf-life; spoilage classification 5 in Table 1 and Supplemental Table S1; https://doi.org/10 $.3168 /$ jds.2017-14216).

For the 24 samples that exceeded $20,000 \mathrm{cfu} / \mathrm{mL}$ but did not show evidence of PPC with gram-negative bacteria either over the shelf-life or in PI samples (spoilage classification 2 in Table 1), gram-positive sporeforming bacteria represented the predominant bacterial contaminants, with a total of 60 gram-positive isolates obtained from these samples. Characterization with a combination of rpoB and 16S rDNA sequencing identified 56 isolates as gram-positive sporeformers in the family Bacillales, with Paenibacillus (43/56) the most prevalent followed by Bacillus (12/56) and Viridibacillus $(1 / 56)$. The remaining gram-positive isolates were nonsporeforming gram-positive bacteria identified as Leuconostoc (4/4). Further, another 64 gram-positive bacteria were isolated from a subset of samples $(\mathrm{n}=26)$ that exceeded 20,000 $\mathrm{cfu} / \mathrm{mL}$ and also showed evidence of PPC (spoilage classification \#3 in Table 1). These gram-positive isolates were identified as Paenibacillus (37/64), Bacillus (18/64), and Viridibacillus (1/64). The remaining gram-positive isolates were nonsporeforming gram-positive bacteria identified as Lactococcus (3/64), Leuconostoc (4/64), and Okibacterium (1/64).

\section{Fluid Milk Samples with Presence of Gram-Negative Bacteria Showed Significantly Reduced Shelf-Life}

A comparison of the mean SPC for each testing day for samples with gram-negative PPC spoilage and samples with gram-positive sporeformer spoilage over 
Table 1. Microbial spoilage pattern for 105 pasteurized milk samples as well as detection pattern for 6 preliminary incubation approaches ${ }^{1}$

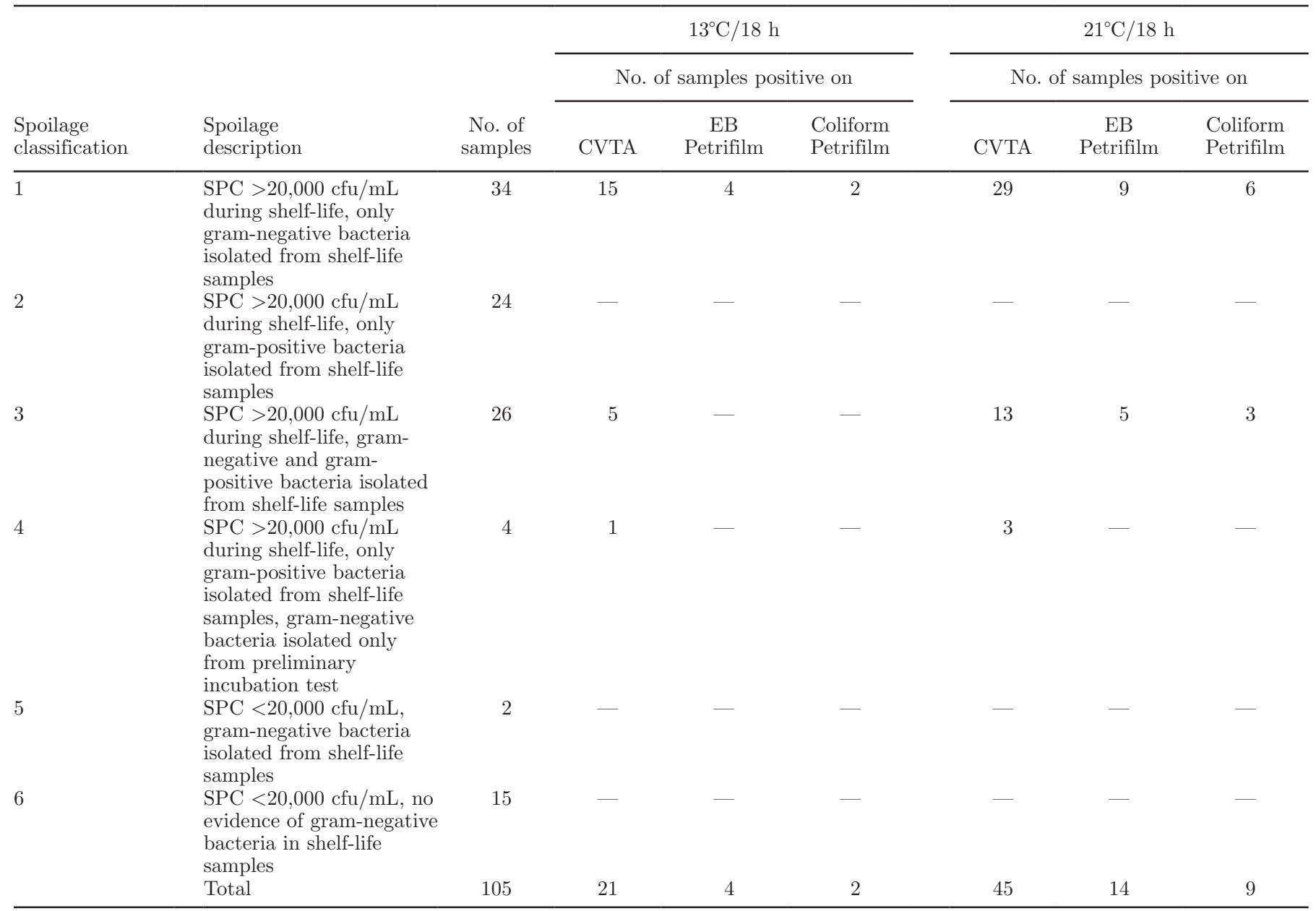

${ }^{1} \mathrm{SPC}=$ standard plate count; $\mathrm{CVTA}=$ crystal violet tetrazolium agar; EB = Enterobacteriaceae. Some samples were positive on more than 1 medium type (e.g., all 4 samples positive on EB Petrifilm after $13^{\circ} \mathrm{C} / 18 \mathrm{~h}$ preliminary incubation were also positive on CVTA). EB Petrifilm and Coliform Petrifilm are from 3M (St. Paul, MN).

the shelf-life showed that samples with gram-negative bacteria had higher $(P<0.05)$ total bacterial counts at d 10, 14, 17, and 21 as compared with samples with gram-positive sporeformers. Mean SPC for samples with gram-positive sporeformer spoilage were 2.5, 2.5, $2.7,3.6,4.8$, and $6.4 \log \mathrm{cfu} / \mathrm{mL}$ on days initial, 7,10 , 14,17 , and 21, respectively, compared with mean SPC for samples with gram-negative PPC spoilage of 1.8, $3.6,5.6,6.9,7.1$, and $7.8 \mathrm{log} \mathrm{cfu} / \mathrm{mL}$ on days initial, 7 , $10,14,17$, and 21 , respectively.

A subset $(\mathrm{n}=90)$ of the samples evaluated also underwent sensory defect analysis; samples were scored on overall acceptability on a scale from 1 to 10 , with a scores of $<6$ designated as poor, 6 to 7 as fair, and 8 to 10 as good (Bodyfelt et al., 1988). The estimated d 14 mean sensory score for samples with gram-positive sporeformer spoilage $(\mathrm{n}=22)$ was 7.98 [95\% CI $(7.74$,
8.20)], whereas the estimated d 14 mean sensory score for samples with gram-negative PPC spoilage ( $\mathrm{n}=$ 46) was 5.78 [95\% CI $(5.62,5.93)]$. Samples with total bacterial counts below $20,000 \mathrm{cfu} / \mathrm{mL}$ on $\mathrm{d} 14(\mathrm{n}=17)$ had an estimated mean sensory score of 8.60 [95\% CI $(8.34,8.85)]$, whereas the remaining 5 samples were not tasted on d 14. Our results also showed that on the final day of shelf-life (either d 14 or 21 depending on previous shelf-life data) the predominant defects identified among the 47 samples with gram-negative PPC spoilage were "coagulated" $(\mathrm{n}=24)$, "lacks freshness" $(\mathrm{n}=11)$, and "bitter" $(\mathrm{n}=10)$. Comparatively, the predominant defects identified among the 22 samples with gram-positive sporeformer spoilage were "lacks freshness" $(\mathrm{n}=8)$ and "not clearly defined" $(\mathrm{n}=6)$; "coagulation" was only rarely identified among these samples $(\mathrm{n}=2$; Figure 1$)$. 
Pre-incubation at $21^{\circ} \mathrm{C}$ Followed by Plating on CVTA Had a Sensitivity of $70 \%$ for Accelerated Detection of Gram-Negative Bacteria

In parallel to the shelf-life testing detailed above, the 105 milk samples were used to evaluate the ability of combinations of different PI schemes (either 13 or $21^{\circ} \mathrm{C}$ for $18 \mathrm{~h}$ ) with subsequent plating on 3 different media that allow for detection of gram-negative organism groups (Coliform Petrifilm, EB Petrifilm, and CVTA) to detect PPC in commercially processed milk. The comprehensive data shown above supported that this set of 105 samples was appropriate for evaluation of different approaches for accelerated detection of gramnegative bacteria in pasteurized milk as these samples represented a wide range of spoilage profiles and different spoilage organisms.

Among the 6 approaches evaluated, a PI of $21^{\circ} \mathrm{C}$ for $18 \mathrm{~h}$ followed by plating on CVTA was the most sensitive, correctly detecting $70 \%$ (42/60) of samples with gram-negative PPC spoilage over the shelf-life (Table 2, Figure 2a). This approach also detected gram-negative contamination in 3 additional samples that did not show evidence of gram-negative PPC spoilage over the shelf-life, resulting in a specificity of $93 \%(42 / 45$;

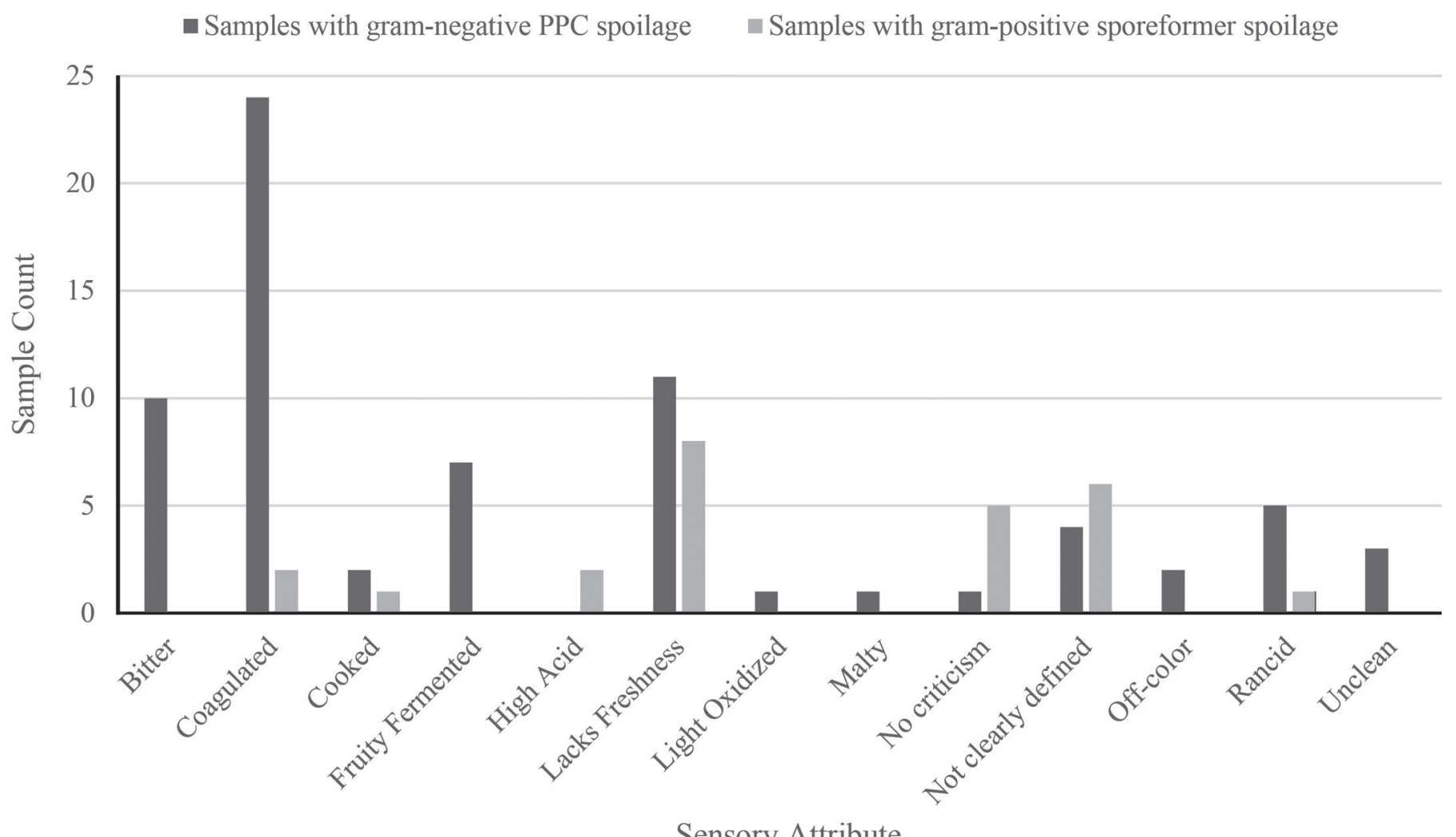

Figure 1. Comparison of sensory defect attributes identified by panelists for samples with gram-negative postpasteurization contamination (PPC) spoilage $(\mathrm{n}=47)$ or gram-positive sporeformer spoilage $(\mathrm{n}=22)$ at the end of the shelf-life (d 14 or 21$)$. spoilage classification \#4 in Table 1). The second most sensitive approach for detection of gram-negative PPC spoilage was a PI of $13^{\circ} \mathrm{C}$ for $18 \mathrm{~h}$ followed by plating on CVTA; this approach correctly identified $33 \%$ $(20 / 60)$ of samples with evidence for gram-negative PPC spoilage over the shelf-life. This approach resulted in a single false positive (i.e., detection of gram-negative organisms with no evidence of gram-negative PPC spoilage over the shelf-life), resulting in a specificity of $98 \%$ (44/45) for detection of gram-negative PPC spoilage (Table 2, Supplemental Figure S1; https://doi.org/ 10.3168/jds.2017-14216). Hence, an overall 4 samples yielded gram-negatives in one of the PI tests, but did not yield gram-negatives in samples tested over the shelf-life [these samples represent spoilage classification 4 (Table 1, Supplemental Table S1, https://doi.org/10 $.3168 /$ jds.2017-14216)]; in these cases the medium used after PI correctly identified gram-negative bacteria, but the positive tests did not correctly identify samples that spoiled due to PPC. The least sensitive test for PPC spoilage was a PI of $13^{\circ} \mathrm{C}$ for $18 \mathrm{~h}$ followed by plating on Coliform Petrifilm; this approach only correctly identified $3 \%(2 / 60)$ of samples with evidence for gram-negative PPC spoilage over the shelf-life (Table 2, Figure 2b).

Samples with gram-positive sporeformer spoilage 
(a.)

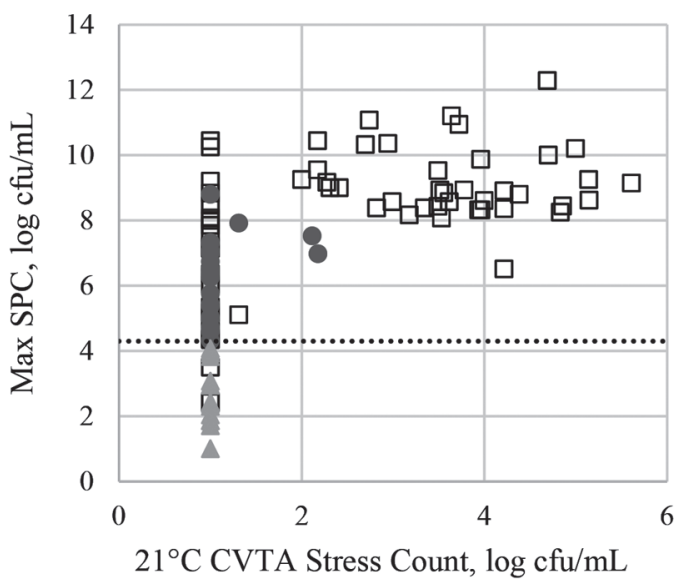

(b.)

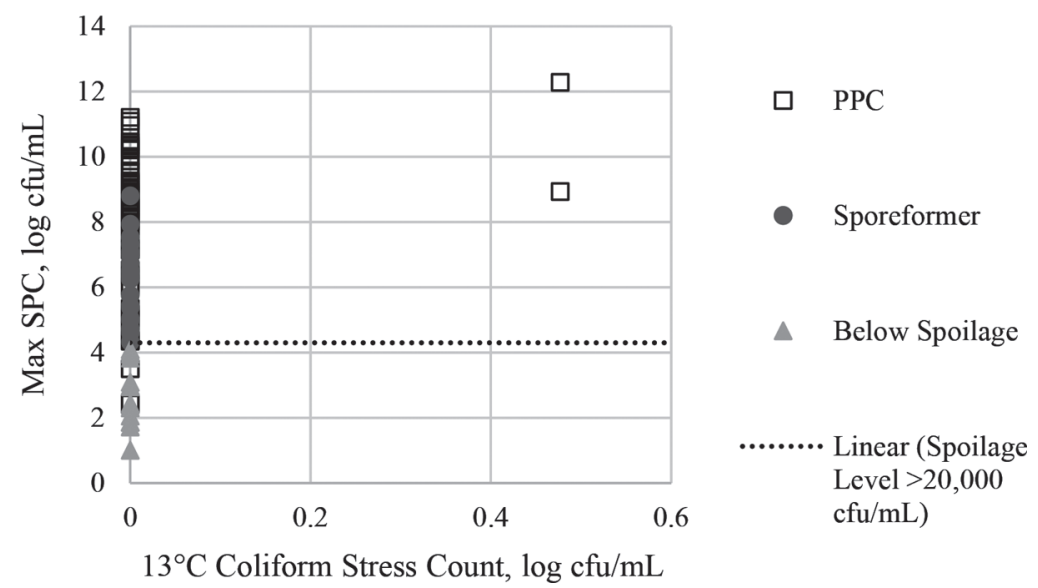

Figure 2. Scatter plots displaying log bacterial counts for samples plated on (a) crystal violet tetrazolium agar (CVTA) after a preliminary incubation at $21^{\circ} \mathrm{C}$ for $18 \mathrm{~h}$ and (b) Coliform Petrifilm (3M, St. Paul, MN) after a preliminary incubation at $13^{\circ} \mathrm{C}$ for $18 \mathrm{~h}$ with corresponding maximum standard plate count (SPC) through shelf-life. Data points are categorized into (1) samples with gram-negative postpasteurization contamination (PPC) spoilage; (2) samples with gram-positive sporeformer spoilage ("sporeformer"); and (3) samples with bacterial counts below $20,000 \mathrm{cfu} / \mathrm{mL}$ ("below spoilage"). The detection limit was $1.0 \log \mathrm{cfu} / \mathrm{mL}$ for SPC and CVTA and 0.0 log cfu/mL for coliforms. Data points for samples that showed no growth on selective media are shown here at the detection limit. A line at $20,000 \mathrm{cfu} / \mathrm{mL}(4.3 \mathrm{log} \mathrm{cfu} / \mathrm{mL}) \mathrm{marks}$ the US Pasteurized Milk Ordinance regulatory limit of $20,000 \mathrm{cfu} / \mathrm{mL}$. Equivalent scatter plots for other media/enrichment combinations can be found in Supplemental Figure S1 (https://doi.org/10.3168/jds.2017-14216).

\section{Total Gram-Negative Test (i.e., CVTA) Detected a Greater Diversity of PPC than EB and Coliform Tests}

Overall, 59 of the 60 samples $(98 \%)$ that showed evidence of gram-negative PPC spoilage over the shelf-life also showed bacterial growth on CVTA on at least one of the samples tested over the shelf-life (Supplemental Table S1; https://doi.org/10.3168/jds.2017-14216). In contrast, EB and Coliform Petrifilm were only positive for $13(22 \%)$ and $12(20 \%)$ of the 60 samples, respectively. Bacterial isolates from these 60 samples as well as the additional 28 samples that exceeded $20,000 \mathrm{cfu} /$
$\mathrm{mL}$ during shelf-life due to gram-positive bacteria, were selected from SPC agar and 3 selective and differential gram-negative medium types (i.e., CVTA, EB Petrifilm, and Coliform Petrifilm) for molecular characterization. Specifically, among a total of 1,005 gram-negative and gram-positive isolates collected from these 88 samples, a subset $(\mathrm{n}=378)$ of isolates was selected to represent the nonredundant diversity of isolates. Only one isolate with a given $r p o B$ sequence or $16 \mathrm{~S}$ rDNA genus obtained for each sample, medium type, and test (i.e., PI or shelf-life) combination was included in this nonredundant set (to avoid overrepresentation of multiple identical isolates from the same test). These 378 nonre-

Table 2. Sensitivity, specificity, positive predictive value, and negative predictive value for 6 different approaches for accelerated detection of fluid milk samples that spoil due to postpasteurization contaminants in 105 pasteurized fluid milk samples

\begin{tabular}{|c|c|c|c|c|c|}
\hline Medium type ${ }^{1}$ & $\begin{array}{c}\text { Preliminary } \\
\text { incubation } \\
\text { temperature }\left({ }^{\circ} \mathrm{C}\right)\end{array}$ & $\begin{array}{c}\text { Sensitivity }^{2} \\
(\%)\end{array}$ & $\begin{array}{c}\text { Specificity }^{3} \\
(\%)\end{array}$ & $\begin{array}{l}\text { Positive } \\
\text { predictive } \\
\text { value }^{4}(\%)\end{array}$ & $\begin{array}{c}\text { Negative } \\
\text { predictive } \\
\text { value }^{5}(\%)\end{array}$ \\
\hline CVTA & 21 & $70(42 / 60)$ & $93(42 / 45)$ & $93(42 / 45)$ & $70(42 / 60)$ \\
\hline EB Petrifilm & 21 & $23(14 / 60)$ & $100(45 / 45)$ & $100(14 / 14)$ & $49(45 / 91)$ \\
\hline Coliform Petrifilm & 21 & $15(9 / 60)$ & $100(45 / 45)$ & $100(9 / 9)$ & $47(45 / 96)$ \\
\hline CVTA & 13 & $33(20 / 60)$ & $98(44 / 45)$ & $95(20 / 21)$ & $52(44 / 84)$ \\
\hline EB Petrifilm & 13 & $7(4 / 60)$ & $100(45 / 45)$ & $100(4 / 4)$ & $44(45 / 101)$ \\
\hline Coliform Petrifilm & 13 & $3(2 / 60)$ & $100(45 / 45)$ & $100(2 / 2)$ & $44(45 / 103)$ \\
\hline
\end{tabular}

${ }^{1} \mathrm{CVTA}=$ crystal violet tetrazolium agar; $\mathrm{EB}=$ Enterobacteriaceae. $\mathrm{EB}$ Petrifilm and Coliform Petrifilm are from 3M (St. Paul, MN).

${ }^{2}$ Sensitivity $=\mathrm{TP} /(\mathrm{TP}+\mathrm{FN}) \times 100 \%(\mathrm{TP}$ : true positive, FN: false negative $)$.

${ }^{3}$ Specificity $=\mathrm{TN} /(\mathrm{TN}+\mathrm{FP}) \times 100 \%$ (TN: true negative, FP: false positive).

${ }^{4}$ Positive predictive value $=\mathrm{TP} /(\mathrm{TP}+\mathrm{FP}) \times 100 \%$.

${ }^{5}$ Negative predictive value $=\mathrm{TN} /(\mathrm{TN}+\mathrm{FN}) \times 100 \%$. 
Table 3. Genera isolated from 88 pasteurized fluid milk samples that exceeded 20,000 cfu/mL during shelf-life on various media

\begin{tabular}{|c|c|c|c|c|c|c|}
\hline Genus $^{1}$ & \multicolumn{4}{|c|}{ No. of isolates obtained on ${ }^{2}$} & Total isolates & $\%$ Total isolates \\
\hline Pseudomonas & 51 & 84 & - & - & 135 & 35.7 \\
\hline Bacillus & 31 & - & - & - & 31 & 8.2 \\
\hline Acinetobacter & 5 & 19 & - & - & 24 & 6.3 \\
\hline Hafnia & 2 & 4 & 4 & 3 & 13 & 3.4 \\
\hline Lelliottia & 2 & - & 4 & 3 & 9 & 2.4 \\
\hline Obesumbacterium & 2 & 1 & 2 & 4 & 9 & 2.4 \\
\hline Leuconostoc & 6 & - & - & - & 6 & 1.6 \\
\hline Aeromonas & 1 & 2 & 3 & - & 6 & 1.6 \\
\hline Rahnella & 1 & - & 2 & 2 & 5 & 1.3 \\
\hline Janthinobacterium & 1 & 3 & - & - & 4 & 1.1 \\
\hline Citrobacter & - & - & 2 & 2 & 4 & 1.1 \\
\hline Viridibacillus & 2 & - & - & - & 2 & 0.5 \\
\hline Stenotrophomonas & 1 & 1 & - & - & 2 & 0.5 \\
\hline Comamonas & - & 2 & - & - & 2 & 0.5 \\
\hline Yersinia & - & - & 2 & - & 2 & 0.5 \\
\hline Okibacterium & 1 & - & - & - & 1 & 0.3 \\
\hline Brevundimonas & - & 1 & - & - & 1 & 0.3 \\
\hline Enterobacter & - & - & - & 1 & 1 & 0.3 \\
\hline Flavobacterium & - & 1 & - & - & 1 & 0.3 \\
\hline Limnohabitans & - & 1 & - & - & 1 & 0.3 \\
\hline Providencia & - & - & 1 & - & 1 & 0.3 \\
\hline Total & 191 & 126 & 34 & 27 & 378 & 100 \\
\hline
\end{tabular}

${ }^{1}$ Genus identification based on partial 16S rDNA and rpoB sequence data. The rpoB data were used for genus identification of the majority of gram-positive isolates.

${ }^{2}$ Numbers indicate the number of isolates collected on each medium type either from shelf-life samples or from positive stress test samples; numbers specifically represent the nonredundant diversity of isolates obtained for each sample, medium type, and test (i.e., stress test or shelflife) combination (meaning only 1 isolate was counted if multiple isolates with the same 16S rDNA or rpoB sequence type were obtained from a given sample, medium type, and test combination). $\mathrm{SPC}=$ standard plate count agar; CVTA = crystal violet tetrazolium agar; EB petrifilm $=$ Enterobacteriaceae. EB Petrifilm and Coliform Petrifilm are from 3M (St. Paul, MN).

dundant isolates were used to compare isolation of different genera and rpoB AT from different media (Table 3). A total of 191 isolates representing 16 genera were isolated from SPC agar, with the predominant genera being Paenibacillus (82/191), Pseudomonas (51/191), and Bacillus (31/191). Among the media that detect gram-negative organisms, CVTA detected the largest number of genera (17 genera among 126 isolates), followed by EB Petrifilm (14 genera among 34 isolates), and Coliform Petrifilm (11 genera among 27 isolates; Table 3). The CVTA captured 9 genera that went undetected by EB Petrifilm and 11 that went undetected on Coliform Petrifilm, with Pseudomonas (84/126) and Acinetobacter (19/126) as the predominant organisms detected on CVTA and not detected on either of the Petrifilm media. Whereas CVTA detected the largest number of genera, EB Petrifilm and Coliform Petrifilm detected 6 and 4 genera, respectively, that were not detected by CVTA (Table 3). It should be noted that in addition to the ability of each medium to support the recovery and growth of different bacterial genera, the isolate selection procedures used in this study may have also contributed to the observation that some genera were only recovered on some media; with characterization of a larger number of isolates from each medium one would expect to see fewer genera that are only detected on a single given medium (specifically EB Petrifilm and Coliform Petrifilm).

\section{DISCUSSION}

\section{Total Gram-Negative Testing Represents a Viable Indicator Test for PPC of Fluid Milk}

Coliforms have been used in the dairy industry since the beginning of the 20th century (Tortorello, 2003) to identify milk that has been processed under unsanitary conditions and contaminated after pasteurization. Coliforms are a method defined group of organisms, primarily within the EB family (Davidson et al., 2004), 
that have been shown historically to play an important role in fluid milk spoilage (Martin et al., 2016). Testing for coliforms in fluid milk is rapid (i.e., 24-48 $\mathrm{h}$ depending on method) and inexpensive. Despite the advantages of using coliforms as indicators of PPC, current research indicates that coliforms are decreasingly prevalent in fluid milk (Carey et al., 2005; Martin et al., 2012). Carey et al. (2005) found that 21 to $34 \%$ of fluid milk samples tested from 1991 to 2000 were positive for coliform, whereas the same group found that from 2001 to 2010 the number of samples positive for coliform on any day of shelf-life ranged from 7.6 to $26.6 \%$ in a given year (Martin et al., 2012). Further, a survey of fluid milk from across the United States found that among 175 gram-negative isolates collected over the shelf-life, only $16.5 \%$ (29/175) were EB and the remainder were non-EB gram-negatives, with Pseudomonas the predominant contaminant $(\mathrm{n}=122$; Ranieri and Boor, 2009). In the current study, $84 \%$ of samples reached spoilage level of bacteria (defined here as $>20,000 \mathrm{cfu} / \mathrm{mL}$ ), due to coliforms, noncoliform EB, non-EB gram-negative bacteria, and gram-positive bacteria, with many samples yielding multiple genera over the shelf-life. Coliforms represented one of the least common groups of contaminants in this study (second only to noncoliform $\mathrm{EB}$, which were only detected in 4 samples; Supplemental Table S1; https://doi.org/10 $.3168 /$ jds.2017-14216).

Similarly to previous studies, Pseudomonas was found in over $86 \%$ of the samples tested here that showed evidence of gram-negative contamination (Supplemental Table S1; https://doi.org/10.3168/jds.2017-14216). Pseudomonas, in the family Pseudomonadaceae, is not a coliform and therefore not detected using coliform test methods but represents a major postpasteurization contaminant in this study and others (Ternström et al., 1993; Eneroth et al., 1998; Deeth et al., 2002). The presence of Pseudomonas in fluid milk not only indicates that PPC has occurred, but also typically has a dramatic effect on the shelf-life of the product. Many Pseudomonas species are not only capable of growing rapidly at refrigeration temperatures (Ternström et al., 1993; Ranieri and Boor, 2009), but also express several enzymes, including proteases and lipases, that degrade the quality of fluid milk (Dogan and Boor, 2003; Nörnberg et al., 2010).

\section{Rapid Detection of Low Level Gram-Negative Contamination that Leads to Product Spoilage Remains a Challenge}

Rapid detection of indicator organisms in fluid milk and accurate shelf-life prediction have long been goals of the dairy industry. The Moseley keeping-quality test
(Moseley, 1980; Duncan et al., 2004), often considered the gold standard, has shown good correlation with fluid milk shelf-life with a study by Bishop and White (1986) reporting a correlation coefficient of -0.77 ; however, this test takes 7 to $9 \mathrm{~d}$ to obtain results. Other tests to predict fluid milk shelf life and detect PPC include a variety of PI methods (e.g., selective enrichment using crystal violet tetrazolium in milk incubated for $18 \mathrm{~h}$ at $21^{\circ} \mathrm{C}$; White, 1993), which typically rely on selective agents to restrict the growth of gram-positive bacteria either in the enrichment or on the plating medium (Griffiths et al., 1984). The current standard method for the PI method, as detailed in the Standard Methods for the Examination of Dairy Products (Duncan et al., 2004), relies on enrichment of $10 \mathrm{~mL}$ of pasteurized milk at $21^{\circ} \mathrm{C}$ for $18 \mathrm{~h}$ followed by plating on standard methods agar, using no selective agents during enrichment or plating (Duncan et al., 2004). Use of selective agents, however, represents a valuable approach that can be used to inhibit the growth of one group of organisms, while still allowing for growth of a targeted set of organisms (e.g., gram-negatives), facilitating simple screening approaches that do not require molecular or other advanced techniques for organism identification. The current study hence tested variations of the standard PI approach on a set of contemporary milk samples that represent current predominant bacterial contaminants, examining different incubation temperatures (i.e., $13^{\circ} \mathrm{C}$ and $21^{\circ} \mathrm{C}$ ) and the use of selective and differential media (i.e., CVTA, EB Petrifilm, and Coliform Petrifilm), all with pre-enrichment of a higher volume of milk (i.e., $100 \mathrm{~mL}$ ) than the standard method. A larger sample volume was specifically used to enhance the sensitivity of the PI method to potentially 1 bacterium per $100 \mathrm{~mL}$, while being realistic about the ability to routinely use large milk volumes in a PI test on larger samples sets. The variations of the PI tests evaluated here showed substantial differences in the sensitivity and specificity of the tests, with regard to early identification of samples that spoiled due to PPC with gram-negative bacteria. Despite the sizeable improvement in sensitivity for detection of gram-negative PPC spoilage by using enrichment at $21^{\circ} \mathrm{C}$ for $18 \mathrm{~h}$ followed by plating on CVTA ( $70 \%$ sensitivity) over the other methods tested (e.g., sensitivity of $3 \%$ for PI at $13^{\circ} \mathrm{C}$ for $18 \mathrm{~h}$ followed by enumeration on Coliform Petrifilm), several samples $(\mathrm{n}=18)$ still showed PPC over the shelf-life, but were not identified with this modified PI test (Table 2, Supplemental Table S1; https:// doi.org/10.3168/jds.2017-14216). We hypothesize that the primary reason for the lack of detection in some samples is a low initial contamination level (around or below 1 cell per $100 \mathrm{~mL}$ ) where 100-mL sub-samples are not consistently positive. We specifically speculate 
that this was the case for 4 of the samples tested here (spoilage classification \#4 in Supplemental Table S1; https://doi.org/10.3168/jds.2017-14216), which allowed for detection of gram-negative bacteria from the enrichment vial (containing $100 \mathrm{~mL}$ of milk), but did not test positive for a gram-negative organism throughout shelf-life. Importantly, although freshly pasteurized milk has been reported to frequently have a total gramnegative count below $1 \mathrm{cfu} / \mathrm{mL}$ (the typical detection limit for direct plating; Schröder, 1984), over the course of refrigerated storage even contaminants at these lower levels can grow to spoilage levels. In theory, as few as 1 bacterial cell introduced after pasteurization per container could result in premature spoilage (Schröder, 1984). In addition to challenges with detection of low levels of gram-negative bacteria, CVTA may also not allow for detection of some gram-negative organisms, as demonstrated in previous work (Hervert et al., 2017); our study here, however, suggests that this may not be a common issue.

The study reported here also clearly demonstrated that, among the media tested here, CVTA recovered the most comprehensive set of gram-negative organisms (Table 3). This is consistent with the predominance of Pseudomonas, which will not grow on EB or Coliform Petrifilm, in fluid milk samples that spoil due to PPC. Van Tassell et al. (2012) also found that CVTA outperformed Coliform Petrifilm, violet red bile agar, and MacConkey agar when enumerating common dairy associated Pseudomonas. Yet, even CVTA has been shown in other studies not to detect certain gram-negative organisms. Specifically, Hervert et al. (2016) found that of a set of 211 previously characterized dairy associated gram-negative bacteria including EB and non-EB strains, 37 failed to grow in pure culture on CVTA. Importantly, Hervert et al. (2016) also found that all of the selective media (CVTA, Coliform and EB Petrifilm, and violet red bile glucose agar) used to evaluate indicator organisms relevant to dairy products showed reduced recovery compared with the nonselective media, BHI agar. Hence, despite the ability of CVTA to detect a more comprehensive set of dairy-associated gram-negative postpasteurization contaminants, as compared with coliform or EB media, further research is needed to identify alternative medium solutions that will detect a broader range of gram-negative organisms associated with contemporary fluid milk PPC, which would improve sensitivity of culture-based tests with regard to detection of PPC.

\section{CONCLUSIONS}

Reducing PPC and thereby providing consumers with the highest quality fluid milk is not only important for the dairy industry to retain customers, but would also play a role in reducing food loss, which is a major issue in the United States. The current study shows that relying on coliform testing is insufficient to detect PPC and leads to underreporting of PPC. To reduce PPC, processors must be able to rapidly and accurately detect PPC events, a goal that clearly is not achievable with current industry testing practices (i.e., coliform testing), particularly as the organisms responsible for PPC of milk continue to shift from coliforms to primarily Pseudomonas. The test presented here (i.e., enrichment of $100 \mathrm{~mL}$ of fluid milk at $21^{\circ} \mathrm{C}$ for $18 \mathrm{~h}$ followed by enumeration on CVTA) not only allows for detection of PPC with a range of organisms, including Pseudomonas, but also is more rapid (allowing for completion in less than 3 full days) relative to traditional methods such as the Moseley keeping quality test, which takes 7 to 9 d. While the PI test detailed above already provides a valuable tool for industry, further research is needed to continue to develop PPC screening methods that have improved sensitivity, increased speed, and increased ease of use; ease of use is a particular concern as the PI method detailed here requires CVTA plates. Briefly, an ideal PPC indicator method should (1) detect low level contamination, which may require testing of larger volumes of product; (2) detect a comprehensive set of PPC organisms, in particular Pseudomonas; (3) have a short time to result, ideally less than $24 \mathrm{~h}$, but certainly less than $48 \mathrm{~h}$, to improve processor response time to contamination events; and (4) be accessible to processors of all sizes and resource levels (favoring methods that are affordable and easy to use).

\section{ACKNOWLEDGMENTS}

The authors acknowledge the contributions of the staff and students of the Milk Quality Improvement Program and the Food Safety Laboratory at Cornell University (Ithaca, NY), notably Sam Reichler, Dave Kent , and Maureen Gunderson. They further acknowledge the New York State Dairy Promotion Advisory Board for supporting this project (OSP\#73039) and their continued commitment to production of highquality dairy products.

\section{REFERENCES}

Altman, D. G., and J. M. Bland. 1994a. Diagnostic tests. 1: Sensitivity and specificity. Br. Med. J. 308:1552.

Altman, D. G., and J. M. Bland. 1994b. Statistics notes: Diagnostic tests 2: Predictive values. Br. Med. J. 309:102.

Bates, D., M. Mächler, B. Bolker, and S. Walker. 2014. Fitting linear mixed-effects models using lme4. J. Stat. Softw. 67:1-48.

Bishop, J. R., and C. H. White. 1986. Assessment of dairy product quality and potential shelf-life-A review. J. Food Prot. 49:739-753. 
Bodyfelt, F. W., J. Tobias, and G. M. Trout. 1988. The Sensory Evaluation of Dairy Products. Van Nostrand Reinhold, New York, NY.

Bossuyt, R. G., and G. M. Waes. 1983. Impedance measurements to detect post-pasteurization contamination of pasteurized milk. J. Food Prot. 46:622-624.

Buzby, J. C., H. Farah-Wells, and J. Hyman. 2014. The estimated amount, value, and calories of postharvest food losses at the retail and consumer levels in the United States. USDA-ERS Economic Information Bulletin Number 121. https://ssrn.com/abstract= 2501659

Byrne, R. D., J. R. Bishop, and J. W. Boling. 1989. Estimation of potential shelf-life of pasteurized fluid milk utilizing a selective preliminary incubation. J. Food Prot. 52:805-807.

Carey, N. R., S. C. Murphy, R. Zadoks, and K. J. Boor. 2005. Shelf lives of pasteurized fluid milk products in New York State: A ten year study. Food Prot. Trends 25:102-113.

Cole, J. R., B. Chai, R. J. Farris, Q. Wang, S. Kulam, D. M. McGarrell, G. M. Garrity, and J. M. Tiedje. 2005. The Ribosomal Database Project (RDP-II): Sequences and tools for high-throughput rRNA analysis. Nucleic Acids Res. 33(Suppl 1):D294-D296.

Davidson, P., L. Roth, and S. Gambrel-Lenarz. 2004. Coliform and other indicator bacteria. Pages 187-226 in Standard Methods for the Examination of Dairy Products. 17th ed. H. M. Wehr and J. F. Frank, ed. American Public Health Association, Washington, DC.

Deeth, H. C., T. Khusniati, N. Datta, and R. B. Wallace. 2002. Spoilage patterns of skim and whole milks. J. Dairy Res. 69:227-241.

Dogan, B., and K. J. Boor. 2003. Genetic diversity and spoilage potentials among Pseudomonas spp. isolated from fluid milk products and dairy processing plants. Appl. Environ. Microbiol. 69:130-138.

Dugan, K., H. Lawrence, D. Hares, C. Fisher, and B. Budowle. 2002. An improved method for post-PCR purification for mtDNA sequence analysis. J. Forensic Sci. 47:811-818.

Duncan, S. E., B. R. Yaun, and S. S. Sumner. 2004. Microbiological methods for dairy products. Pages 249-268 in Standard Methods for the Examination of Dairy Products. H. M. Wehr and J. F. Frank, ed. American Public Health Association, Washington, DC.

Eneroth, Å., A. Christiansson, J. Brendehaug, and G. Molin. 1998. Critical contamination sites in the production line of pasteurised milk, with reference to the psychrotrophic spoilage flora. Int. Dairy J. 8:829-834.

FDA (US Food and Drug Administration). 2015. Standards for grade "A" milk and milk products. Pages 34-35 in Grade "A" Pasteurized Milk Ordinance. Standards for Grade "A" Milk and Milk Products. US Department of Health and Human Services, Public Health Service, Washington, DC.

Griffiths, M. W. 1993. Applications of bioluminescence in the dairy industry. J. Dairy Sci. 76:3118-3125.

Griffiths, M. W., J. D. Phillips, and D. D. Muir. 1984. Methods for rapid detection of post-pasteurization contamination in cream. Int. J. Dairy Technol. 37:22-26.

Gruetmacher, T. J., and R. L. Bradley Jr.. 1999. Identification and control of processing variables that affect the quality and safety of fluid milk. J. Food Prot. 62:625-631.

Hayes, W. C. H. White, and M. A. Drake. 2002. Sensory aroma characteristics of milk spoilage by Pseudomonas species. J. Food Sci. $67: 448-454$.

Hervert, C., A. Alles, N. Martin, K. Boor, and M. Wiedmann. 2016. Evaluation of different methods to detect microbial hygiene indicators relevant in the dairy industry. J. Dairy Sci. 99:7033-7042.

Hervert, C., N. Martin, K. Boor, and M. Wiedmann. 2017. Survival and detection of coliforms, Enterobacteriaceae, and gram-negative bacteria in Greek yogurt. J. Dairy Sci. 100:950-960.
Huck, J. R., N. H. Woodcock, R. D. Ralyea, and K. J. Boor. 2007. Molecular subtyping and characterization of psychrotolerant endospore-forming bacteria in two New York State fluid milk processing systems. J. Food Prot. 70:2354-2364.

Ivy, R. A., M. L. Ranieri, N. H. Martin, H. C. den Bakker, B. M. Xavier, M. Wiedmann, and K. J. Boor. 2012. Identification and characterization of psychrotolerant sporeformers associated with fluid milk production and processing. Appl. Environ. Microbiol. 78:1853-1864.

Laird, D. T., S. A. Gambrel-Lenarz, F. M. Scher, T. E. Graham, and R. Reddy. 2004. Microbiological Count Methods. Chapter 6 in Standard Methods for the Examination of Dairy Products. H. M. Wehr and J. F. Frank, ed. American Public Health Association, Washington, DC.

Lenth, R. V. 2016. Least squares means: The R package lsmeans. J. Stat. Softw. 69:1-33.

Martin, N. H., N. R. Carey, S. C. Murphy, M. Wiedmann, and K. J. Boor. 2012. A decade of improvement: New York State fluid milk quality. J. Dairy Sci. 95:7384-7390.

Martin, N. H., A. Trmčić, T.-H. Hsieh, K. J. Boor, and M. Wiedmann. 2016. The evolving role of coliforms as indicators of unhygienic processing conditions in dairy foods. Front. Microbiol. 7:1549.

McGinnis, S., and T. L. Madden. 2004. BLAST: At the core of a powerful and diverse set of sequence analysis tools. Nucleic Acids Res. 32(Suppl_2):W20-W25.

Moseley, W. 1980. Pinpointing post-pasteurization contamination. J. Food Prot. 43:414.

Nörnberg, M. F. B. L., R. S. C. Friedrich, R. D. N. Weiss, E. C. Tondo, and A. Brandelli. 2010. Proteolytic activity among psychrotrophic bacteria isolated from refrigerated raw milk. Int. J. Dairy Technol. 63:41-46.

Ralyea, R. D., M. Wiedmann, and K. J. Boor. 1998. Bacterial tracking in a dairy production system using phenotypic and ribotyping methods. J. Food Prot. 61:1336-1340.

Ranieri, M., and K. Boor. 2009. Short communication: Bacterial ecology of high-temperature, short-time pasteurized milk processed in the United States. J. Dairy Sci. 92:4833-4840.

Schröder, M. J. 1984. Origins and levels of post pasteurization contamination of milk in the dairy and their effects on keeping quality. J. Dairy Res. 51:59-67.

Schröder, M. J. A., C. M. Cousins, and C. H. McKinnon. 1982. Effect of psychrotrophic post-pasteurization contamination on the keeping quality at 11 and $5{ }^{\circ} \mathrm{C}$ of HTST-pasteurized milk in the UK. J. Dairy Res. 49:619-630.

Ternström, A. A. M. Lindberg, and G. Molin. 1993. Classification of the spoilage flora of raw and pasteurized bovine milk, with special reference to Pseudomonas and Bacillus. J. Appl. Bacteriol. $75: 25-34$.

Tortorello, M. L. 2003. Indicator organisms for safety and quality - Uses and methods for detection: minireview. J. AOAC Int $86: 1208-1217$

Trmcic, A., N. H. Martin, K. J. Boor, and M. Wiedmann. 2015. A standard bacterial isolate set for research on contemporary dairy spoilage. J. Dairy Sci. 98:5806-5817.

Van Tassell, J. A., N. H. Martin, S. C. Murphy, M. Wiedmann, K. J. Boor, and R. A. Ivy. 2012. Evaluation of various selective media for the detection of Pseudomonas species in pasteurized milk. J. Dairy Sci. 95:1568-1574.

White, C. H. 1993. Rapid methods for estimation and prediction of shelf-life of milk and dairy products. J. Dairy Sci. 76:3126-3132.

Wickham, H. 2016. ggplot2: Elegant Graphics for Data Analysis. Springer, New York, NY. 